\title{
Attitudes about cannabis mediate the relationship between cannabis knowledge and use in active adult athletes
}

\author{
Joanna S. Zeiger ${ }^{1 *}$, William S. Silvers ${ }^{1,2}$, Edward M. Fleegler ${ }^{1,3}$ and Robert S. Zeiger ${ }^{1,4}$
}

\begin{abstract}
Background: Little is known about how cannabis knowledge and attitudes impact cannabis use behavior.

Objective: To test the knowledge-attitudes-behavior paradigm in active adult athletes.

Design: The Athlete Pain, Exercise, and Cannabis Experience (PEACE) Survey, a cross-sectional survey study, used social media and email blasts to recruit participants and SurveyGizmo to collect data.

Participants: Self-defined active adult athletes $(n=1161)$.

Main measures: Knowledge about cannabis was evaluated with four questions. Attitudes toward cannabis was evaluated with 11 questions. The attitudes questions were used in a TwoStep Cluster analysis in SPSS to assign group membership by attitudes. Chi-square was used to determine if there were differences in cluster membership by demographic factors and if knowledge about cannabis differed by cluster membership. Regression analysis was performed to determine if cannabis attitudes mediated the relationship between cannabis knowledge and cannabis use.
\end{abstract}

Key results: A three-cluster solution was the best fit to the data. The clusters were named Conservative ( $n=374$, $32.2 \%)$, Unsure $(n=533,45.9 \%)$, and Liberal $(n=254,21.9)$. There was a significant difference among the clusters for all 11 attitudes items (all $p<0.001$ ). Attitude cluster membership was significantly different by age $(p<0.001)$, primary sport $(p<0.05)$, and knowledge about cannabis $(p<0.001)$. Athletes in the liberal cluster answered the knowledge questions correctly most often. Attitudes mediated the relationship between cannabis knowledge and cannabis use [Never (32.4\%), Past (41.6\%), Current (26.0\%)] with athletes in the liberal cluster showing more knowledge and greater likelihood to be a current cannabis user $(p<0.001)$. Among current cannabis users there were differential patterns of cannabis use depending on their attitudes and knowledge; liberal athletes tended to co-use THC and CBD and used cannabis longer. $(p<0.001)$.

Conclusions: Cannabis education needs to consider attitudes about cannabis, especially among those who might benefit from medical cannabis.

Keywords: Medical cannabis, Cannabis education, Cluster analysis, Athletes, Attitudes, Cannabis

\footnotetext{
*Correspondence: joannazeiger@comcast.net

${ }^{1}$ Canna Research Group, 3996 Savannah Ct, Boulder, CO 80301, USA

Full list of author information is available at the end of the article
}

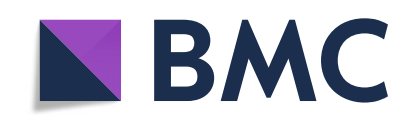

(- The Author(s). 2020 Open Access This article is licensed under a Creative Commons Attribution 4.0 International License, which permits use, sharing, adaptation, distribution and reproduction in any medium or format, as long as you give appropriate credit to the original author(s) and the source, provide a link to the Creative Commons licence, and indicate if changes were made. The images or other third party material in this article are included in the article's Creative Commons licence, unless indicated otherwise in a credit line to the material. If material is not included in the article's Creative Commons licence and your intended use is not permitted by statutory regulation or exceeds the permitted use, you will need to obtain permission directly from the copyright holder. To view a copy of this licence, visit http://creativecommons.org/licenses/by/4.0/. 


\section{Background}

The inter-relatedness of attitudes and behavior has been evaluated both conceptually and practically (Fazio 1986; Fazio et al. 1983; Bocquier et al. 2005; Bernhardsson et al. 2014). Early theories of the connection between attitudes and behavior were considered "guiding" or "influential" (Fazio et al. 1983) and that this process was oneto-one, ignoring the presence of other potential variables that might impact this relationship (Fazio 1986). It is now widely believed that other factors may change the attitude-behavior relationship with knowledge being one such intervening variable (Fazio 1986; Macaulay et al. 2005; Borden et al. 2008). The relationship between knowledge, attitudes, and behavior is theoretically important, particularly when knowledge and attitudes are impacting deleterious behavior or are needed to boost positive behavior.

The triad of knowledge-attitudes-behavior has not been well studied in terms of cannabis use, but previous studies have taken a harms-avoidance approach examining drug use in adolescents. A study of parenting practices and adolescent drug use tested adolescent drug knowledge, pro-drug attitudes, and adolescent drug use (Macaulay et al. 2005). Pro-drug attitudes predicted both knowledge about drugs and drug use (Macaulay et al. 2005). Another study in adolescents showed that education regarding substance use impacted substance use attitudes which decreased cigarette smoking and cannabis use (Botvin et al. 1990).

The growing popular acceptance of cannabis use among the US population is leading to increasing use, thus warranting the evaluation of the knowledgeattitudes-behavior paradigm (Manzanares et al. 2006; Abuhasira et al. 2018; Green et al. 2003). The four most common reasons for medical cannabis use in a recent study were chronic pain, anxiety, insomnia, and stress with cannabis used as a substitute for prescription drugs (e.g. opiates, anti-depressants, nonopioid pain medicine), alcohol, and illicit substances) (Lucas et al. 2019). Education regarding the therapeutic benefits of cannabis and proper ways to administer cannabis may change attitudes and downstream cannabis use behavior reducing the adverse effects of cannabis (O'Connell et al. 2019).

Despite the growing evidence for the efficacy of cannabis to treat a variety of medical conditions, adverse effects to cannabis are known and educational programs should focus on the potential harms as well as the potential benefits (Zeiger et al. 2019a; Black et al. 2019; Volkow et al. 2014). A recent meta-analysis examining the use of medical cannabis for psychiatric disorders such as ADHD, depression, Tourette Syndrome, and anxiety found that high quality studies are lacking (Black et al. 2019). However, among the studies that were included in the analysis, the authors stated "We found little evidence for the effectiveness of pharmaceutical CBD or medicinal cannabis for the treatment of any of these mental disorders [mentioned above]. Some verylow quality evidence was found for the use of pharmaceutical THC (with or without CBD) in treating anxiety symptoms among individuals with other medical conditions, such as chronic non-cancer pain and multiple sclerosis." (Black et al. 2019) Furthermore, adverse effects of addiction, impaired motor-coordination, paranoia, psychosis, emergency room visits for vomiting, cognitive impairment, and altered brain development are potential side effects of both short and long term cannabis use (Volkow et al. 2014; Metrik et al. 2011). There has been conflicting evidence around the efficacy of cannabis to alleviate the burden of opioid overdose mortality (Shover et al. 2019).

Cannabis use in athletes has been a contentious issue, as it has been viewed primarily as an area of concern due to anti-doping laws and abuse potential (Ware et al. 2018; Hainline et al. 2017; Brisola-Santos et al. 2016). .Caucasian male athletes who participate in high risk sports (e.g. bobsled, ice hockey, and skeleton) used cannabis more often than other athlete groups and many athletes used cannabis as a means to improve their sports performance (Brisola-Santos et al. 2016). Cannabis has the potential to diminish performance due to reducing alertness and reaction time as well as accelerating muscle fatigue (Gil et al. 2016). However, studies examining both benefits and adverse effects, as well as knowledge and attitudes, regarding cannabis in adult athletes have been overlooked in favor of studies examining risk (Gil et al. 2016; McDuff et al. 2019).

Our study, The Athlete Pain, Exercise, and Cannabis Experience (PEACE) Survey, examined cannabis patterns of use and subjective effects to cannabis in self-defined community-based adult athletes (Zeiger et al. 2019a). Largely, the positive effects of cannabis, including improved sleep, decreased pain, and reduced anxiety, outweighed adverse effects of decreased concentration, increased appetite, and anxiety (Zeiger et al. 2019a). With 49\% of athletes indicating they have acute or chronic pain, potential therapies to mitigate the pain are needed; indeed, 69\% reported that cannabis reduced their pain (Zeiger et al. 2019a). Age-related differences in patterns of use and subjective effects to cannabis were observed in this population (Zeiger et al. 2019b).

The Athlete PEACE Survey also measured cannabis knowledge and attitudes. The aim of this analysis was to understand the relationship between attitudes, knowledge and cannabis use. We hypothesized that cannabis attitudes mediated the relationship between cannabis knowledge and cannabis use in active adult athletes. 


\section{Methods}

This secondary analysis was conducted using data from The Athlete PEACE Survey, a cross-sectional quantitative survey study designed to characterize cannabis use in a convenience sample of self-defined athletes (see paper for survey questions and detailed sample characteristics) (Zeiger et al. 2019a). The survey was administered on SurveyGizmo (https://www.surveygizmo.com) between 6 September 2018 and 7 December 2018 and was approved with waiver of written consent by Solutions IRB (http://www.solutionsirb.com). Participants were assured confidentiality and were informed that "by completing and submitting this survey, you are indicating your consent to participate in the study". Inclusion criteria included: (1) ages 21 years or older, (2) a selfdeclared athlete of any sport, and (3) English speaking, with no other inclusions or exclusions. Social media sites such as Facebook, Twitter, and LinkedIn were the primary sources of recruitment. The call to action (Additional file 1) was posted on sports specific Facebook pages as well as on sports specific forums. A web page was set up on a secure website with a link to the study survey. The recruitment material was also posted to endurance sports websites and LinkedIn. There was no paid advertising for the study. Leaflets were left in stores that represented a variety of sports. Email blasts with the call to action were sent out and were shared by other coaches and athletes. The survey module was created to maximize completion of all questions. As such, no data points were missing. The cohort is multi-national $(83.5 \%$ from the United States) and represents all fifty states. Even though the call-to-action was placed on multiple sport sites, triathletes, cyclists, and runners were the most highly represented athlete groups. Athletes from these sports tend to be early adopters of novel modalities and are very active on message boards, Facebook pages, and forums (Etxebarria et al. 2019; MultiSport Research 2018). All the 1161 subjects in the study analyses completely filled out the questionnaire (Table 1).

There were 113 incomplete surveys in which there was not enough information to impute data or use any of the existing data. Eleven questions regarding cannabis attitudes were used from the questionnaire from the Attitudes on Marijuana Survey conducted by the Hazelden Betty Ford Foundation and Q Market Research (Table 2) (Q Market Research 2015).

Four questions were asked to measure general knowledge about cannabis (Table 3).

The SPSS TwoStep cluster analysis procedure was used to create cannabis attitudes groups. Cluster analysis can be used to divide data into smaller groups with similar characteristics when there are no a priori assumptions about differences within the population; it creates homogenous groups within heterogenous data (Ehlert et al. 2017; Punj and Stewart 1983). Cluster analysis was used to identify attitudes phenotypes to determine how these phenotypes relate to knowledge about cannabis and cannabis use. All eleven attitudes questions were used in the cluster analysis.

A systematic analysis of sample sizes for cluster analyses reviewed 243 cluster analyses and found that the median sample size for the cluster analyses was 293 participants (Dolcinar et al. 2014). A simulation study found valid solutions for cluster analysis with samples as small as 20 (Henry et al. 2015). The present sample size of 1161 was adequate for this analysis.

The SPSS TwoStep Cluster is appropriate for large datasets where hierarchical clustering can be cumbersome and difficult to interpret and when the number of clusters is not known a priori. The TwoStep Cluster can determine both the number of clusters and allocate subjects to their respective clusters. The first step is a preclustering which uses a sequential clustering approach and then a final clustering using an agglomerative hierarchical clustering method (Bacher et al. 2004). The log-likelihood method with the BIC goodness-of-fit was used whereby a large ratio of distances is considered an optimal number of clusters (Bacher et al. 2004). Once clusters were identified, post-hoc tests were conducted to determine whether there was inter-cluster heterogeneity (i.e. the distribution of subjects per cluster) and intra-cluster homogeneity (chi-square tests to examine cluster separation) (Table 1).

The four knowledge questions had a single correct answer and four incorrect answers. The four question were converted into a knowledge score by summing the four answers, where a correct answer was " 1 " and an incorrect answer was " 0 ", with a minimum score of 0 and a maximum score of 4 . ANOVA was used to determine whether there were attitudes cluster differences in mean knowledge scores (Table 3).

Cannabis use was measured with two questions: (1) "Have you ever used marijuana?" to which the answers were "yes" or "no" and (2) "In the past two weeks, have you used marijuana (including THC and/or CBD)?" to which the answers were "yes" or "no". "Never users" answered no to the first question, "Past users" answered yes to the first question and no to the second question and "current users" answered yes to both questions.

Regression analysis was performed to test whether cannabis attitudes mediate the relationship between knowledge and use. Fig. 1, Panel A depicts the Knowledge, Attitude, and Behavior Cognitive Model (Fig. 1, Panel A) (Chatterjee et al. 2009; Valente et al. 1998; Baranowski et al. 2003). This model postulates that first an individual must learn about a behavior, then they develop an attitude toward that behavior which might lead to initiation of a behavior (Valente et al. 
Table 1 Demographics by cannabis use status in 1161 adult athletes [Data as N (\%)]

\begin{tabular}{|c|c|c|c|c|c|}
\hline Variable & Category & $\begin{array}{l}\text { Total } \\
(\boldsymbol{N}=1161)\end{array}$ & $\begin{array}{l}\text { Current User } \\
(\boldsymbol{N}=302)\end{array}$ & $\begin{array}{l}\text { Ever, not current User } \\
(\boldsymbol{N}=483)\end{array}$ & $\begin{array}{l}\text { Never User } \\
(\boldsymbol{N}=376)\end{array}$ \\
\hline \multirow[t]{2}{*}{$\overline{S e x^{1}}$} & Male & $722(62.2)$ & $182(60.3)$ & $312(64.6)$ & $228(60.6)$ \\
\hline & Female & $437(37.6)$ & $120(39.7)$ & $170(35.2)$ & $147(39.1)$ \\
\hline \multirow[t]{2}{*}{$\mathrm{Age}^{*}$} & $21-39$ & $374(32.2)$ & $122(40.4)$ & $139(28.8)$ & $113(30.1)$ \\
\hline & 40 and over & $787(67.8)$ & $180(59.6)$ & $344(71.2)$ & $263(69.9)$ \\
\hline \multirow[t]{2}{*}{ Ethnicity } & Caucasian & $1042(89.8)$ & $269(89.1)$ & $439(90.9)$ & 334 (88.8) \\
\hline & Other & $119(10.2)$ & $33(10.9)$ & $44(9.1)$ & $42(11.2)$ \\
\hline \multirow[t]{4}{*}{ Primary Sportt** } & Running & $299(25.8)$ & $75(24.8)$ & $113(23.4)$ & $111(29.5)$ \\
\hline & Cycling & $258(22.2)$ & $69(22.8)$ & $111(23.0)$ & $78(20.7)$ \\
\hline & Triathlon & $399(34.4)$ & $73(24.2)$ & $184(38.1)$ & $142(37.8)$ \\
\hline & Other* & $205(17.7)$ & $85(28.1)$ & $75(15.5)$ & $45(12.0)$ \\
\hline \multirow[t]{2}{*}{ Days per week exercise** } & $1-4$ days & $309(26.6)$ & $112(37.1)$ & $116(24.0)$ & $81(21.5)$ \\
\hline & $5-7$ days & $852(73.4)$ & $190(62.9)$ & $367(76.0)$ & $295(78.5)$ \\
\hline \multirow[t]{5}{*}{ Athlete Status* } & Professional & $25(2.2)$ & $11(3.6)$ & $7(1.4)$ & $7(1.9)$ \\
\hline & Serious/competitive (amateur) & $468(40.3$ & $100(33.1)$ & $202(41.8)$ & $166(44.1)$ \\
\hline & Frequent/fitness athlete & 405 (34.9) & $100(33.1)$ & $179(37.1)$ & $126(33.5)$ \\
\hline & Recreational athlete & $243(20.9)$ & $86(28.5)$ & $87(18.0)$ & 70 (18.6) \\
\hline & Other & $20(1.7)$ & $5(1.7)$ & $8(1.7)$ & $7(1.9)$ \\
\hline \multirow[t]{3}{*}{ Pain** } & No pain & $592(51.0)$ & $118(39.1)$ & $261(54.0)$ & $213(56.6)$ \\
\hline & $<3$ months & $94(8.1)$ & $30(9.9)$ & $34(7.0)$ & $30(8.0)$ \\
\hline & 3 or more months & $475(40.9)$ & $154(51.0)$ & $188(38.9)$ & $133(35.4)$ \\
\hline \multirow[t]{2}{*}{ Country** } & United States & $969(83.5)$ & $300(79.8)$ & $396(82.0)$ & $274(90.7)$ \\
\hline & Other & $192(16.5)$ & $76(20.2)$ & $87(18.0)$ & $28(9.3)$ \\
\hline \multirow[t]{3}{*}{ Cannabis legal in state or country** } & Yes & $583(50.2)$ & $170(45.2)$ & $218(45.1)$ & $195(64.6)$ \\
\hline & No & $532(45.8)$ & $184(48.9)$ & $247(51.1)$ & $101(33.4)$ \\
\hline & Unsure & $46(4.0)$ & $22(5.9)$ & $18(3.7)$ & $6(2)$ \\
\hline
\end{tabular}

*Modified from Zeiger et al. (2019) (Zeiger et al. 2019a); ${ }^{1}$ Not all numbers add to 1161 due to two participants declining to answer the question. Chi-square test for group differences by cannabis use status: * $p<0.01 ;{ }^{* *} p<0.001$

Other sports breakdown: Swimming, 62; Strength training/gym, 29; Trail running, 19; Hiking, 14; Walking, 10; Winter sports (skiing, snowboarding, snow shoeing), 9; Yoga/Pilates, 7; Spartan races, 7; Climbing, 6; Martial arts/MMA, 5; Hockey, 5; Multiple sports, 3; Dance, 3; Soccer, 2; Baseball/, 4; Tennis, 2; Collegiate Soccer/HIIT/ Crossfit, 2; Duathlon, 2; Roller derby, 2; Lacrosse, 2; Motor sports / horseback riding, 1; Multiple racquet sports, 1; Pilates, 1; Rebounding, 1; Boxing, 1; Rugby, 1; Sailing, 1; Softball, 1; Rowing, 1; Aquabike, 1; Archery, 1;

1998). The present analysis tests this model using cannabis knowledge, attitudes and use (i.e. behavior) as the measured domains with the potential of attitudes mediating the relationship between knowledge and behavior (Fig. 1, Panel B).

Mediation regression analysis was performed using the PROCESSv3.2 command in SPSS (Hayes 2017). A variable $M$ is a mediator when $X$ significantly predicts $Y, X$ significantly predicts $\mathrm{M}$ and $\mathrm{M}$ significantly predicts $Y$ (after controlling for $X$ ). A mediator variable is in a causal relationship between two variables (MacKinnon et al. 2007). PROCESS examines the direct effect from $X$ (causal variable) to $\mathrm{Y}$ (outcome variable) and the indirect effect through $M$ (mediator). The "model 4" designation was chosen. PROCESS calculates the coefficients of 5 paths, from $X$ to $M$ (the "a" path), from $M$ to $Y$ (the " $b$ " path), the total effect (from $\mathrm{X}$ to $\mathrm{Y}$ without adjusting for the mediator, the " $\mathrm{c}$ " path), and the direct effect (from $\mathrm{X}$ to $\mathrm{Y}$ adjusting for the mediator, the " $\mathrm{c}$ " path) and the indirect effect of $\mathrm{X}$ to $\mathrm{Y}$. Direct effects are those effects not impacted by the mediator while indirect effects are the effects which are potentially affected by a mediator (Hayes 2017). If there is mediation, the direct effect should become smaller with the addition of the mediator variable (MacKinnon et al. 2007).

The bootstrapping method of 5000 samples was used to test for the indirect effects; mediation occurs if the 95\% confidence intervals estimated by the bootstrapping method do not overlap 0 . Results are presented as standardized beta coefficients. 
Table 2 Attitudes toward cannabis in adult athletes by cluster membership. [Data as N (\%)]

\begin{tabular}{|c|c|c|c|c|}
\hline Attitude question & Response & Conservative $(n=374)$ & Unsure $(n=533)$ & Liberal $(n=254)$ \\
\hline \multirow[t]{3}{*}{ Do you think marijuana is addictive? \pm} & Yes & $228(61)$ & $125(23.5)$ & $0(0)$ \\
\hline & No & $43(11.5)$ & $221(41.5)$ & $254(100)$ \\
\hline & Unsure & $103(27.5)$ & $187(35.1)$ & $0(0)$ \\
\hline \multirow[t]{3}{*}{ Do you think marijuana is damaging to the brain? \pm} & Yes & $285(76.2)$ & $131(24.6)$ & $0(0)$ \\
\hline & No & $17(4.5)$ & $112(21)$ & $254(100)$ \\
\hline & Unsure & $72(19.3)$ & $290(54.4)$ & $0(0)$ \\
\hline \multirow{3}{*}{$\begin{array}{l}\text { Do you think consuming edible marijuana is safer } \\
\text { than smoking it? } \pm\end{array}$} & Yes & $100(26.7)$ & $324(60.8)$ & $150(59.1)$ \\
\hline & No & $137(36.6)$ & $62(11.6)$ & $56(22.0)$ \\
\hline & Unsure & $137(36.6)$ & $147(27.6)$ & $48(18.9)$ \\
\hline \multirow{3}{*}{$\begin{array}{l}\text { Do you think marijuana is less harmful to your health } \\
\text { than alcohol? } \pm\end{array}$} & Yes & $38(10.2)$ & $373(70)$ & $235(92.5)$ \\
\hline & No & $198(52.9)$ & $12(2.3)$ & $9(3.5)$ \\
\hline & Unsure & $138(36.9)$ & $148(27.8)$ & $10(3.9)$ \\
\hline \multirow{3}{*}{$\begin{array}{l}\text { Do you think marijuana is less harmful to your } \\
\text { health than tobacco? } \pm\end{array}$} & Yes & 77 (20.6) & 452 (84.8) & $240(94.5)$ \\
\hline & No & 179 (47.9) & $8(1.5)$ & $8(3.1)$ \\
\hline & Unsure & 118 (31.6) & 73 (13.7) & $6(2.4)$ \\
\hline \multirow{3}{*}{$\begin{array}{l}\text { Do you think legalizing marijuana makes it } \\
\text { seem safer? } \pm\end{array}$} & Yes & $176(47.1)$ & $400(75)$ & 202 (79.5) \\
\hline & No & $142(38)$ & $82(15.4)$ & $39(15.4)$ \\
\hline & Unsure & $56(15.0)$ & $51(9.6)$ & $13(5.1)$ \\
\hline \multirow{3}{*}{$\begin{array}{l}\text { Do you think marijuana can be beneficial for people } \\
\text { with certain medical conditions? } \pm\end{array}$} & Yes & 297 (79.4) & 524 (98.3) & $254(100)$ \\
\hline & No & $18(4.8)$ & $0(0)$ & $0(0)$ \\
\hline & Unsure & 59 (15.8) & $9(1.7)$ & $0(0)$ \\
\hline \multirow{3}{*}{$\begin{array}{l}\text { Do you think legalizing marijuana makes it more } \\
\text { socially acceptable? } \pm\end{array}$} & Yes & $255(68.2)$ & 487 (91.4) & $246(96.9)$ \\
\hline & No & $81(21.7)$ & $23(4.3)$ & $5(2.0)$ \\
\hline & Unsure & $38(10.2)$ & $23(4.3)$ & $3(1.2)$ \\
\hline \multirow{3}{*}{$\begin{array}{l}\text { Do you support the legalization of marijuana for } \\
\text { medical purposes? } \pm\end{array}$} & Yes & 265 (70.9) & $529(99.2)$ & $254(100)$ \\
\hline & No & $46(12.3)$ & $1(0.2)$ & $0(0)$ \\
\hline & Unsure & $63(16.8)$ & $3(0.6)$ & $0(0)$ \\
\hline \multirow{3}{*}{$\begin{array}{l}\text { Do you support the legalization of marijuana } \\
\text { for recreational purposes? } \pm\end{array}$} & Yes & 64 (17.1) & 388 (72.8) & 249 (98) \\
\hline & No & $248(66.3)$ & $45(8.4)$ & $4(1.6)$ \\
\hline & Unsure & 62 (16.6) & 100 (18.8) & $1(0.4)$ \\
\hline \multirow[t]{3}{*}{ Do you think athletes who use marijuana are doping? \pm} & Yes & $181(48.4)$ & $47(8.8)$ & $5(2)$ \\
\hline & No & $103(27.5)$ & $383(71.9)$ & $231(90.9)$ \\
\hline & Unsure & $90(24.1)$ & $103(19.3)$ & $18(7.1)$ \\
\hline
\end{tabular}

\section{Comparisons of Column Proportions ${ }^{b}$}

TwoStep Cluster Number Conservative

Unsure Liberal

(A) (B)

(C)

(B) $\quad(C$

Do you think marijuana is addictive?

Yes

B

No

A

Unsure

A

Do you think marijuana is damaging to the brain?

Yes

B

No

Unsure

\section{A}

A

Yes

$$
\text { a }
$$

Do you think consuming edible marijuana is safer 
Table 2 Attitudes toward cannabis in adult athletes by cluster membership. [Data as N (\%)] (Continued)

\begin{tabular}{|c|c|c|c|c|}
\hline \multirow[t]{2}{*}{ than smoking it? } & No & $B C$ & & $\mathrm{~B}$ \\
\hline & Unsure & B C & C & \\
\hline \multirow{3}{*}{$\begin{array}{l}\text { Do you think marijuana is less harmful to your } \\
\text { health than alcohol? }\end{array}$} & Yes & & A & $A B$ \\
\hline & No & B C & & \\
\hline & Unsure & $B C$ & C & \\
\hline \multirow{3}{*}{$\begin{array}{l}\text { Do you think marijuana is less harmful to your } \\
\text { health than tobacco? }\end{array}$} & Yes & & A & $A B$ \\
\hline & No & B C & & \\
\hline & Unsure & B C & C & \\
\hline \multirow[t]{3}{*}{ Do you think legalizing marijuana makes it seem safer? } & Yes & & A & A \\
\hline & No & B C & & \\
\hline & Unsure & $B C$ & & \\
\hline \multirow{3}{*}{$\begin{array}{l}\text { Do you think marijuana can be beneficial for people } \\
\text { with certain medical conditions? }\end{array}$} & Yes & & A & $a^{a}$ \\
\hline & No & & 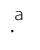 & $a^{a}$ \\
\hline & Unsure & B & & $a^{a}$ \\
\hline \multirow{3}{*}{$\begin{array}{l}\text { Do you think legalizing marijuana makes it } \\
\text { more socially acceptable? }\end{array}$} & Yes & & A & $A B$ \\
\hline & No & B C & & \\
\hline & Unsure & B C & & \\
\hline \multirow{3}{*}{$\begin{array}{l}\text { Do you support the legalization of marijuana } \\
\text { for medical purposes? }\end{array}$} & Yes & & A &. \\
\hline & No & B & & a \\
\hline & Unsure & B & & a \\
\hline \multirow{3}{*}{$\begin{array}{l}\text { Do you support the legalization of marijuana } \\
\text { for recreational purposes? }\end{array}$} & Yes & & A & $A B$ \\
\hline & No & BC & C & \\
\hline & Unsure & C & C & \\
\hline \multirow[t]{3}{*}{ Do you think athletes who use marijuana are doping? } & Yes & B C & C & \\
\hline & No & & A & $A B$ \\
\hline & Unsure & C & C & \\
\hline
\end{tabular}

Results are based on two-sided tests. For each significant pair, the key of the category with the smaller column proportion appears in the category with the larger column proportion

Significance level for upper case letters (A, B, C): .05

a. This category is not used in comparisons because its column proportion is equal to zero or one

b. Tests are adjusted for all pairwise comparisons within a row of each innermost sub-table using the Bonferroni correction

Chi-square p-values: ${ }^{ \pm} p<0.001$

All analyses were conducted in IBM SPSS Statistics for Windows, version 24.0 (2016). Significance was considered at $P<0.05,2$-sided.

\section{Results}

\section{Cluster analysis}

A two-cluster solution was automatically designated with a BIC of $17,815.29$ (BIC change: - 3172.98). A visual inspection of a three-cluster solution was deemed a better to fit to the data, with a BIC of 16 , 894.19 (BIC change: -921.11). A four-class solution was not appropriate based on the BIC change for a three-class solution $(-921.107)$ vs. a four-class solution (-556.030). Pairwise comparisons of a four-class solution did not show statistically significant differences between classes 3 and 4 for most of the variables. Table 2 shows the frequencies and chi-square $p$-values for the attitude's questions by cluster membership; all questions were significantly different between clusters at $p<0.001$. Furthermore, pairwise comparisons of the proportions show that each cluster is distinct from the other clusters for all of the attitude's questions. The clusters were named Conservative $(n=374,32.2 \%)$, Unsure $(n=533$, $45.9 \%)$, and Liberal $(n=254,21.9 \%)$. The clusters were named based on the predominant answers to the questions. The "Conservative" group primarily thought cannabis is addictive (66\%), damaging to the brain $(76.2 \%)$, more harmful than tobacco $(47.9 \%)$ and alcohol (52.9\%), and the majority do not support legalization for recreational purposes (66.3\%). This contrasts to the "Liberal" group in which $98 \%$ support legalization for recreational purposes, $100 \%$ did not think cannabis is addictive or damaging to the brain; 
Table 3 Knowledge about cannabis in 1161 adult athletes by attitudes cluster. Correct answers are bolded [Data as N (\%)]

\begin{tabular}{|c|c|c|c|c|}
\hline Knowledge questions & Cannabis type & Conservative $(n=374)$ & Unsure $(n=533)$ & Liberal $(n=254)$ \\
\hline \multirow[t]{5}{*}{ Which cannabinoid is psychoactive? \pm} & THC & $203(54.3)$ & $421(79)$ & $214(84.3)$ \\
\hline & CBD & $3(0.8)$ & $4(0.8)$ & $3(1.2)$ \\
\hline & Both & $13(3.5)$ & $5(0.9)$ & $10(3.9)$ \\
\hline & Neither & $5(1.3)$ & $2(0.4)$ & $3(1.2)$ \\
\hline & Don't know & $150(40.1)$ & $101(18.9)$ & $24(9.4)$ \\
\hline \multirow{5}{*}{$\begin{array}{l}\text { Which cannabinoid has therapeutic } \\
\text { benefits that can offer symptom relief } \\
\text { to people with pain? } \pm\end{array}$} & THC & $12(3.2)$ & $20(3.8)$ & $6(2.4)$ \\
\hline & CBD & $138(36.9)$ & $262(49.2)$ & $124(48.8)$ \\
\hline & Both & $68(18.2)$ & $165(31)$ & $99(39)$ \\
\hline & Neither & $6(1.6)$ & $1(0.2)$ & $0(0)$ \\
\hline & Don't know & $150(40.1)$ & $85(15.9)$ & $25(9.8)$ \\
\hline \multirow{5}{*}{$\begin{array}{l}\text { Which cannabinoid is attributed with } \\
\text { reducing seizures in patients who suffer } \\
\text { from epilepsy? } \pm\end{array}$} & $\mathrm{THC}$ & $32(8.6)$ & $42(7.9)$ & $10(3.9)$ \\
\hline & CBD & $96(25.7)$ & $227(42.6)$ & $138(54.3)$ \\
\hline & Both & $30(8.0)$ & $69(12.9)$ & 49 (19.3) \\
\hline & Neither & $4(1.1)$ & $2(0.4)$ & $0(0)$ \\
\hline & Don't know & $212(56.7)$ & $193(36.2)$ & $57(22.4)$ \\
\hline \multirow{5}{*}{$\begin{array}{l}\text { The majority of strains available today } \\
\text { have been selectively bred for high concentrations } \\
\text { of which cannabinoid? } \pm\end{array}$} & THC & $95(25.4)$ & $236(44.3)$ & $110(43.3)$ \\
\hline & CBD & $44(11.8)$ & $77(14.4)$ & 37 (14.6) \\
\hline & Both & $32(8.6)$ & $54(10.1)$ & $53(20.9)$ \\
\hline & Neither & $1(0.3)$ & $2(0.4)$ & $0(0)$ \\
\hline & Don't know & $202(54.0)$ & $164(30.8)$ & $54(21.3)$ \\
\hline Mean score $(S D)^{*}$ & & $1.23(1.19)$ & $1.97(1.17)$ & $2.21(1.10)$ \\
\hline
\end{tabular}

Chi-square $p$-values: ${ }^{ \pm} p<0.001 ;{ }^{*}$ ANOVA $p$-value $<0.001$

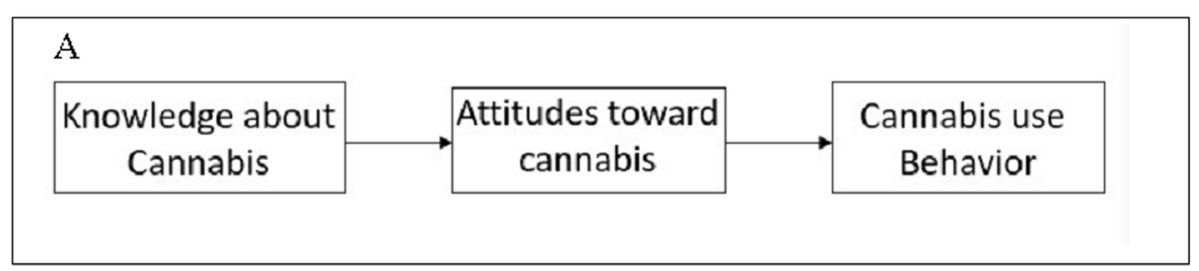

B

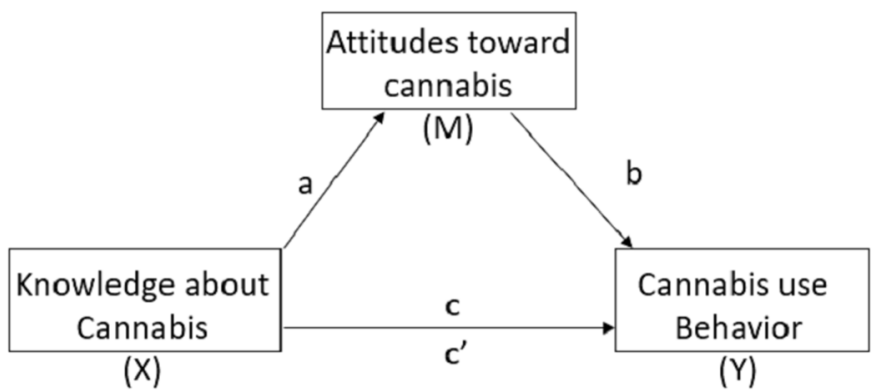

Fig. 1 Panel a shows Knowledge, Attitudes, Behavior Model. Panel b shows the proposed Mediation Model of Knowledge, Attitudes, and Behavior regarding cannabis 
and, 92.5 and $94.5 \%$ thought alcohol and tobacco, respectively, are more harmful than cannabis. The "Unsure" group fell somewhere in the middle with $35.1 \%$ unsure whether cannabis is addictive and $54.4 \%$ indicated that cannabis is damaging to the brain and 27.8 and $13.7 \%$ were unsure whether cannabis is less harmful to health than alcohol or tobacco, respectively. Almost 19\% were unsure whether they support recreational legalization of cannabis.

There were no gender differences between clusters (Table 4), but there were age differences, with younger athletes more often in the Liberal cluster $(p<$ 001). Triathletes were the most conservative and athletes in the "Other" group were the most Liberal $(p<$ $0.01)$. Athletes in states or countries in which cannabis use is legal were more often in the Liberal cluster $(p<0.05)$. These variables were added to the mediation models but were not significant and ultimately not included in the final models. Never users of cannabis were more often in the Conservative cluster, Past Users were more often in the Unsure cluster, and Current users were mainly in the Liberal cluster $(p<0.001)$.

\section{Knowledge measurement}

The total mean score for knowledge was 1.78 (SD: 1.22) and the mean knowledge scores for the three clusters were: Conservative (m: 1.24, SD: 1.19), Unsure (m: 1.97, SD: 1.17), Liberal (m: 2.21, SD: 1.10). These differences were statistically significant $(\mathrm{F}=$ 65.34, 2 DF, $p<0.001)$. A post-hoc Bonferroni test indicated that all three groups were statistically significantly different from each other at $p<0.001$ (except for Liberal and Unsure, $p<0.05$ ). There was a statistically significant difference in mean knowledge scores by cannabis use status ( $\mathrm{F}=134.21,2 \mathrm{DF}, p<0.001)$. The means by cannabis use status were: never users $(1.21, \quad \mathrm{SD}=1.15)$, past users $(1.72, \mathrm{SD}=1.16)$ and current users $(2.60, \mathrm{SD}=0.95)$ and a post-hoc Bonferroni test showed that all three groups were significantly different from each other (all $p<0.001$ ).

Table 4 Cannabis use attitudes clusters and demographics in adult athletes [Data as N (\%)]

\begin{tabular}{|c|c|c|c|c|}
\hline \multirow[t]{2}{*}{ Variables } & \multirow[t]{2}{*}{ Category } & \multicolumn{3}{|l|}{ Cluster } \\
\hline & & Conservative $(n=374)$ & Unsure $(n=533)$ & Liberal $(n=254)$ \\
\hline \multirow[t]{2}{*}{ Gender } & Male & $239(64.1)$ & $326(61.3)$ & $157(61.8)$ \\
\hline & Female & $134(35.9)$ & $206(38.7)$ & $97(38.2)$ \\
\hline \multirow[t]{2}{*}{ Age $\neq$} & 21 to 39 & $83(22.2)$ & $186(34.9)$ & $105(41.3)$ \\
\hline & 40 and older & $291(77.8)$ & $347(65.1)$ & $149(58.7)$ \\
\hline \multirow[t]{4}{*}{ Primary Sport† } & Running & $103(27.5)$ & $134(25.1)$ & $62(24.4)$ \\
\hline & Cycling & $92(24.6)$ & $115(21.6)$ & $51(20.1)$ \\
\hline & Triathlon & $137(36.6)$ & $185(34.7)$ & $77(30.3)$ \\
\hline & Other & $42(11.2)$ & 99 (18.6) & $64(25.2)$ \\
\hline \multirow[t]{5}{*}{ Level of competitiveness (type of athlete) } & Professional & $4(1.1)$ & $13(2.4)$ & $8(3.1)$ \\
\hline & Serious amateur & $169(45.2)$ & $198(37.1)$ & $101(39.8)$ \\
\hline & Frequent/fitness & $127(34.0)$ & $203(38.1)$ & $75(29.5)$ \\
\hline & Recreational & $68(18.2)$ & $110(20.6)$ & 65 (25.6) \\
\hline & Other & $6(1.6)$ & $9(1.7)$ & $5(2.0)$ \\
\hline \multirow[t]{5}{*}{ Hours/week exercise } & $0-5 \mathrm{~h}$ & $37(9.9)$ & $63(11.8)$ & $22(8.7)$ \\
\hline & $6-10 h$ & $172(46.0)$ & $220(41.3)$ & $111(43.7)$ \\
\hline & $11-15 h$ & $117(31.3)$ & $169(31.7)$ & $87(34.3)$ \\
\hline & $16-20 \mathrm{~h}$ & $37(9.9)$ & $63(11.8)$ & $23(9.1)$ \\
\hline & more than $20 \mathrm{~h}$ & $11(2.9)$ & $18(3.4)$ & $11(4.3)$ \\
\hline \multirow{3}{*}{$\begin{array}{l}\text { Is marijuana legal in your state or country } \\
\text { (if not in the United States)?* }\end{array}$} & Yes & $171(45.7)$ & $266(49.9)$ & $146(57.5)$ \\
\hline & No & $183(48.9)$ & $248(46.5)$ & $101(39.8)$ \\
\hline & Unsure & $20(5.3)$ & $19(3.6)$ & $7(2.8)$ \\
\hline \multirow[t]{3}{*}{ Cannabis Useł } & Current & $13(3.5)$ & $146(27.4)$ & $143(56.3)$ \\
\hline & Past Use & $141(37.7)$ & $250(46.9)$ & $92(36.2)$ \\
\hline & Never & $220(58.8)$ & $137(25.7)$ & $19(7.5)$ \\
\hline
\end{tabular}




\section{Mediation}

The relationship between knowledge about cannabis and cannabis use was significantly mediated by attitudes toward cannabis and explained $34 \%$ of the overall variance for cannabis use $\left(\mathrm{R}^{2}=0.34, \mathrm{~F}(2,1158)=293.01, p<.001\right)$. As Fig. 2 illustrates, the "a" path from knowledge to attitudes was statistically significant $(0.18, p<0.001)$ as was the " $b$ " path from attitudes to cannabis use $(0.43, p<$ 0.001). This indicates that athletes with the most knowledge tended to have the most liberal attitudes about cannabis and were more likely to be cannabis users. The direct effect $(c=0.19, p<0.001)$ and total effect of cannabis knowledge use were statistically significant (c' = $0.27(p<0.001)$. Finally, the indirect effect was $0.08(95 \%$ CI: 0.06-0.09) which was statistically significant, indicating that attitudes toward cannabis mediated the relationship between knowledge about cannabis and cannabis use.

\section{Discussion}

This secondary analysis of the cross-sectional Athlete PEACE Survey study is the first to identify the mediating effect of cannabis attitudes on knowledge and cannabis use. Cannabis knowledge impacted cannabis use directly and indirectly through cannabis attitudes. Athletes were clustered into three attitudes groups: Conservative, Unsure, and Liberal. Liberal and Unsure athletes tended to score better on the knowledge questions and were more likely to be current cannabis users rather than never users or past users compared to the Conservative cluster.

Previous studies regarding the impact of attitudes and knowledge on cannabis use have examined the direct or mediating effects of parental knowledge on their child's drug use (Macaulay et al. 2005; Sellers et al. 2018; Wu et al. 2015). Parental knowledge indirectly influenced adolescent cannabis use through the number of offers of cannabis (Siegel et al. 2015), when adolescent-reported parental knowledge increased, adolescent alcohol use decreased (Sellers et al. 2018), and maternal knowledge had direct and indirect effects on adolescent substance use (Wang et al. 2009). In adults, attitudes mediated the relationship between information seeking and intention to use cannabis, but actual cannabis use was not measured (Martinez and Lewis 2016).

While it is not possible to directly measure causality with cross-sectional studies, research examining Knowledge-Attitude-Behavior relationships have been cross-sectional for practical reasons and to test hypotheses that can guide interventional studies (Valente et al. 1998; Baranowski et al. 2003; Fairchild and McDaniel 2017). Cross-sectional studies are considered appropriate for mediation analysis if confounding is addressed and the temporal relationship of the variables can be established given the measured constructs (Fairchild and McDaniel 2017). We addressed the potential confounders of age, gender, and duration of cannabis use by adding them to the mediation model; none of these variables were significant and were not included in the final model. A review of knowledge, attitudes, and substance use disorder included nine epidemiologic studies which measured all three dimensions contemporaneously and concluded "Lack of knowledge on the risks of substance use has contributed to the increasing cases of substance use disorders. Substance use has been attributed to lack of proper knowledge on the associated risks." (Njoroge

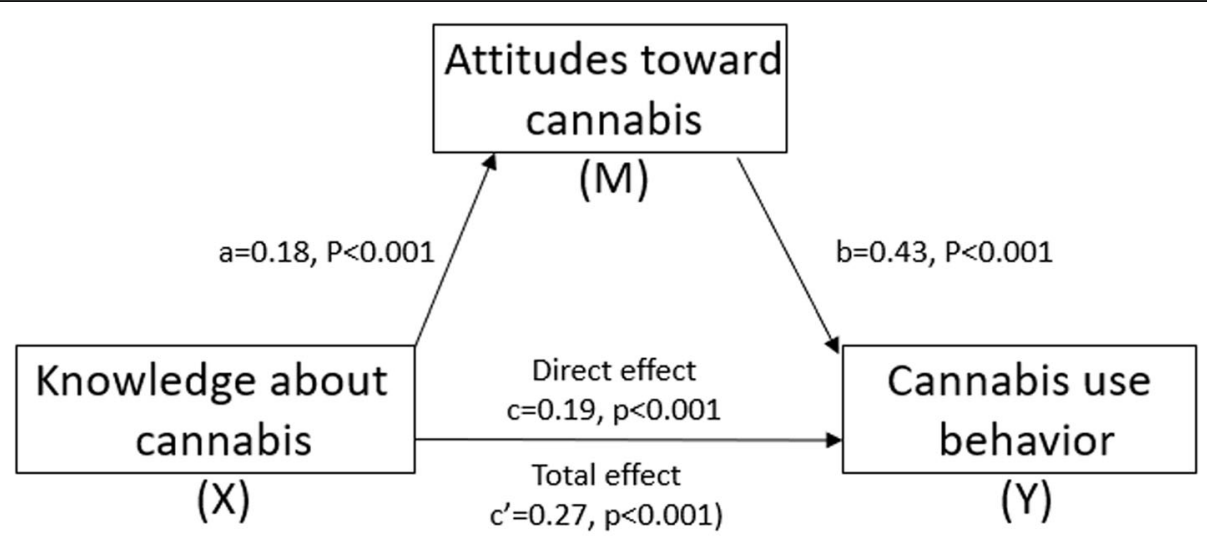

Indirect effect: $0.08,95 \% \mathrm{Cl}: 0.06-0.09$

Fig. 2 Mediation analysis of attitudes, knowledge, and cannabis use in adult athletes. Effects are standardized coefficients. The $X$ to $M$ path is the effect of knowledge about cannabis on attitudes toward cannabis. Attitudes is coded as $1=$ Conservative, $2=$ Unsure, $3=$ Unsure; Conservative is the comparison group. Knowledge is continuous $0-4$. The $M$ to $Y$ path is the effect of attitudes toward cannabis on cannabis use. Cannabis use is coded as: 1 = Never use, 2 = Past Use, $3=$ Current Use. The Direct effect is the effect of knowledge on use adjusted for attitudes. The Total effect is the effect of knowledge on use without considering attitudes 
and Kenyatta 2017) With respect to this study, knowledge about cannabis which originates from multiple sources throughout an athlete's lifetime precedes their attitudes toward cannabis which then impacts their decision making on whether to use cannabis. Certainly, this study is a snapshot, taken at one point in time, whereby all three domains could change by shifting knowledge and/or attitudes (e.g. providing accurate knowledge about cannabis may change an athlete's attitude and thusly change their behavior).

Medical cannabis has received increased attention due to its potential positive impact on chronic pain, fibromyalgia, inflammatory bowel disease, and other difficult to treat conditions (Bachhuber et al. 2019; Sagy et al. 2019; Ahmed and Katz 2016; Park and Wu 2017). Traditionally, the study of cannabis has been through the lens of reducing use and abuse, with only limited research into benefits from cannabis (Satterlund et al. 2015). Even among the Conservative attitudes cluster in these analyses, 79.4\% reported that medical cannabis can be beneficial for people with certain medical conditions and 71\% supported medical legalization. Thus, there is still a disconnect between knowledge and attitudes regarding cannabis which could impact behavior, particularly among medical professionals who may be asked by patients to give advice on cannabis use (Berlekamp et al. 2019; Moeller and Woods 2015; Chan et al. 2017).

Given the significant impact of knowledge on cannabis use behavior, the source of knowledge is of utmost importance, particularly given the expanding legalization of cannabis at the state level. Often, the primary source of medical cannabis advice comes from dispensary staff (i.e. budtenders) (Peiper et al. 2017; Wang et al. 2009; Martinez and Lewis 2016). Medical training for budtenders is lacking, with only $20 \%$ reporting specific medical or scientific training, yet $94 \%$ provided cannabis advice to patients (Haug et al. 2016). This lack of training has seen $69 \%$ of surveyed budtenders recommend cannabis products as a treatment for morning sickness in pregnant Colorado women (Dickson et al. 2018), despite the known harmful effects of cannabis use in pregnancy in increasing preterm birth (Corsi et al. 2019). Pharmacists in Minnesota believed there was insufficient training in cannabis pharmacotherapy and were not aware of statewide regulations, however there was interest in educational programs (Hwang et al. 2016). Pharmacy students poorly identified qualifying medical conditions and adverse effects and they did not feel confident about answering questions about medical marijuana; only $13 \%$ indicated formal education on medical marijuana during their training (Moeller and Woods 2015). Colorado medical students had favorable attitudes toward cannabis, however, they did not feel comfortable recommending it, due to lack of evidence and training (Chan et al. 2017).
Underscoring how knowledge and attitudes can potentially affect cannabis use, $12.5 \%$ of the Conservative attitudes cluster in this sample indicated they do not use cannabis because they are scared but only $2.7 \%$ of the Liberal attitudes cluster chose this as a reason not to use cannabis while the Unsure cluster fell in the middle at $8.3 \%$ (this difference was significant, $p<0.01$ ). Proper education from informed budtenders and medical professionals could potentially alleviate fear and lack of understanding about the benefits and adverse effects of cannabis. The importance of this undertaking and the need for evidence-based education is clear; unabated or improper cannabis use has increased emergency room visits for cannabis hyperemesis syndrome and psychotic episodes (Monte et al. 2019).

Since this is a convenience sample recruited via multiple sources, it is not possible to know the total number of athletes who saw the call to action and therefore cannot determine the refusal rate. This is a study limitation. The representativeness of this sample to the wider sporting community is unknown. Comparisons to the latest statistics from the governing body of triathlon (USA Triathlon) and cycling (USA Cycling) show that the participant demographics in this sample roughly match the overall populations. The runners in this sample skew male which is different than the sex composition found by Running USA (USA Triathlon 2016; Running 2017; https://legacy.usacycling.org/corp/demographics.php n.d.). Even though the sample demographics roughly reflect those of the greater population of triathletes, runners, and cyclists, the participants are self-selected, therefore the cannabis attitudes clusters and knowledge about cannabis may not be representative of athletes in general. Our data show the following male percentages for the three main sports: $53 \%$ running, $81.3 \%$ cycling, and 63.45 triathlon. USA Triathlon most recently reported their membership is $65 \%$ male (USA Triathlon 2016), while $85.3 \%$ of USA Cycling's member are male (https://legacy.usacycling.org/corp/demographics.php n.d.) and $43 \%$ of runners are male (Running 2017). In terms of age of triathletes, $12.8 \%$ are $25-29,35.6 \%$ are $30-39,29.4 \%$ are $40-49$, and $13.5 \%$ are over 50 (USA Triathlon 2016); this compares to our numbers of $14 \%$ $21-29,22.6 \% 30-39,28.6 \% 40-49$ and $34.9 \%$ over 50 . USA Cycling shows that $28.0 \%$ of their members are 19-34 and $63.7 \%$ are 35 and older (https://legacy.usacycling.org/corp/demographics.php n.d.); $13.5 \%$ of our participants who cycled were 21-39. Half of all runners were $25-44$ years old (Running 2017) while $62.2 \%$ of our runners were over 40 .

We recognize that the knowledge and attitudes expressed by this sample may not be representative of other demographic groups. The attitudes observed in this sample were similar to those found in a sample of 
New York college students (Q Market Research 2015). It is reassuring that the relationship between knowledge, attitudes, and behavior has been observed in other domains (Kuhlemeier et al. 1999; Register-Mihalik et al. 2013; Ozisik et al. 2017). The large sample size allowed for adequate clustering of the data and the mediation regression analysis. In addition, the sample represented a large age-range and varying experience with cannabis use, both of which can impact knowledge and attitudes (Gates et al. 2017; Berlekamp et al. 2019; Moeller and Woods 2015).

It has been noted that cross-sectional data may not be appropriate for mediation analysis, particularly if a process is changing over time (O'Laughlin et al. 2018). The Knowledge-Attitude-Behavior model postulates the temporal ordering, as was succinctly stated by Baranowski et al.: "As knowledge accumulates in a health behavior domain, changes in attitude are initiated. Over some period of time, changes in attitude accumulate, resulting in behavioral change." (Baranowski et al. 2003) Furthermore, the present analysis provides important insights: (1) cannabis epidemiology is a nascent field, thus obtaining information to direct future epidemiologic studies is an essential first step; (2) longitudinal studies are not necessarily the only way to examine the Knowledge-Attitude-Behavior relationship and often are not feasible to conduct (Buckner et al. 2019; Ball et al. 2018; Stubbs et al. 2018; Buckner et al. 2018); and (3) future interventional study can test this model.

In conclusion, these mediation analyses indicated that cannabis attitudes appeared to mediate the effect of knowledge on use. As more states legalize medical and recreational cannabis, proper consumer, budtender, and medical professional education will become paramount to the safety and efficacy of cannabis use.

\section{Supplementary information}

Supplementary information accompanies this paper at https://doi.org/10. 1186/s42238-020-00023-3.

Additional file 1. Call to Action for The Athlete PEACE Survey

\section{Abbreviations}

THC: Tetrahydrocannabinol; CBD: Cannabidiol; The Athlete PEACE Survey: The Athlete Pain, Exercise, and Cannabis Experience Survey; KAB model: Knowledge-Attitudes-Behavior

\section{Acknowledgements}

We gratefully acknowledge the participants and those who shared our survey link.

\section{Authors' contributions}

JSZ was responsible for the conception of the study, study design, questionnaire development, participant recruitment, data analysis, manuscript preparation. EMF and WSS helped with study design, conceptualization and manuscript review. RSZ made substantial contribution to development of the questionnaire, interpretation of the data, and critical review of the manuscript. The authors read and approved the final manuscript.

Funding

The study was self-funded by the authors.

\section{Availability of data and materials}

The datasets used and/or analyzed during the current study are available from the corresponding author on reasonable request.

\section{Ethics approval and consent to participate}

This study was approved by Solutions, IRB with waived consent. Consent was given by filling out the survey.

Consent for publication

Not applicable.

\section{Competing interests}

The authors declare that there are no competing interests.

\section{Author details}

${ }^{1}$ Canna Research Group, 3996 Savannah Ct, Boulder, CO 80301, USA.

${ }^{2}$ Division of Allergy and Clinical Immunology, University of Colorado Denver School of Medicine, 12700 E. 19th Ave., Room 10C03, Aurora, CO 80045, USA.

${ }^{3}$ To-Life in Peace, LLC, 3812 Taft Court, Wheat Ridge, CO 80033, USA. ${ }^{4}$ Kaiser Permanente Southern California, 7060 Clairemont Mesa Blvd, San Diego, CA 92111, USA

Received: 11 October 2019 Accepted: 2 April 2020

Published online: 18 May 2020

\section{References}

Abuhasira R, Schleider LB-LL, Mechoulam R, Novack V. Epidemiological characteristics, safety and efficacy of medical cannabis in the elderly. Eur J Intern Med. 2018;49:44-50. https://doi.org/10.1016/j.ejim.2018.01.019.

Ahmed W, Katz S. Therapeutic use of cannabis in inflammatory bowel disease. Gastroenterol Hepatol (N Y). 2016;12:668-79 http://www.ncbi.nlm.nih.gov/ pubmed/28035196. Accessed 16 Aug 2019.

Bacher J, Wenzig K, Vogler M. SPSS TwoStep cluster - a first evaluation. Univ Erlangen-nürnb. 2004;1:1-20.

Bachhuber M, Arnsten JH, Wurm G. Use of cannabis to relieve pain and promote sleep by customers at an adult use dispensary. J Psychoactive Drugs. 2019: 02791072.2019.1626953. https://doi.org/10.1080/02791072.2019.1626953.

Ball JE, Bruyneel L, Aiken LH, Sermeus W, Sloane DM, Rafferty AM, et al. Postoperative mortality, missed care and nurse staffing in nine countries: a crosssectional study. Int J Nurs Stud. 2018;78:10-5. https://doi.org/10.1016/J. IJNURSTU.2017.08.004.

Baranowski T, Cullen KW, Nicklas T, Thompson D, Baranowski J. Are current health behavioral change models helpful in guiding prevention of weight gain efforts? Obes Res. 2003;11:23S-43S. https://doi.org/10.1038/oby.2003.222.

Berlekamp D, Rao PSS, Patton T, Berner J. Surveys of pharmacy students and pharmacy educators regarding medical marijuana. Curr Pharm Teach Learn. 2019;11:669-77. https://doi.org/10.1016/j.cptl.2019.03.006.

Bernhardsson S, Johansson K, Nilsen P, Oberg B, Larsson MEH. Determinants of guideline use in primary care physical therapy: a cross-sectional survey of attitudes, knowledge, and behavior. Phys Ther. 2014;94:343-54. https://doi. org/10.2522/ptj.20130147

Black N, Stockings E, Campbell G, Tran LT, Zagic D, Hall WD, et al. Cannabinoids for the treatment of mental disorders and symptoms of mental disorders: a systematic review and meta-analysis. Lancet Psychiatry. 2019;6:995-1010.

Bocquier A, Verger P, Basdevant A, Andreotti G, Baretge J, Villani P, et al. Overweight and obesity: knowledge, attitudes, and practices of genera practitioners in France. Obes Res. 2005;13:787-95. https://doi.org/10.1038/ oby.2005.89.

Borden LM, Lee S-A, Joyce AE, Ae S, Collins D, Borden LM, et al. Changing college students' financial knowledge, attitudes, and behavior through seminar participation. J Fam Econ Iss. 2008;29:23-40. https://doi.org/10.1007/ s10834-007-9087-2.

Botvin GJ, Baker E, Dusenbury L, Tortu S, Botvin EM. Preventing adolescent drug abuse through a multimodal cognitive-behavioral approach: results of a 3Yar study. J Consult Clin Psychol. 1990;58:437-46 http://citeseerx.ist.psu.edu/ 
viewdoc/download?doi=10.1.1.562.1635\&rep=rep1\&type=pdf. Accessed 15 Aug 2019.

Brisola-Santos MB, Gallinaro JG de ME, Gil F, Sampaio-Junior B, Marin MCD, de Andrade AG, et al. (2016) Prevalence and correlates of cannabis use among athletes-a systematic review. Am J Addict 25:518-528 doi:https://doi.org/10. 1111/ajad.12425.

Buckner JD, Walukevich KA, Henslee AM. Event-specific cannabis use and cannabis use motives. Subst Use Misuse. 2018;53:1093-8. https://doi.org/10. 1080/10826084.2017.1399142

Buckner JD, Walukevich KA, Lewis EM. Cannabis use motives on weekends versus weekdays: direct and indirect relations with cannabis use and related problems. Addict Behav. 2019;88:56-60. https://doi.org/10.1016/J.ADDBEH. 2018.08.012.

Chan MH, Knoepke CE, Cole ML, McKinnon J, Matlock DD. Colorado medical students' attitudes and beliefs about marijuana. J Gen Intern Med. 2017;32: 458-63. https://doi.org/10.1007/s11606-016-3957-y.

Chatterjee J, Bhanot A, Frank LB, Murphy S, Power G. The importance of interpersonal discussion and self-efficacy in knowledge, attitude, and practice models. Int J Commun. 2009;3:28 https://pdxscholar.library.pdx.edu/comm_ $\mathrm{fac} / 29 /$. Accessed 1 Oct 2019.

Corsi DJ, Walsh L, Weiss D, Hsu H, El-Chaar D, Hawken S, et al. Association between self-reported prenatal cannabis use and maternal, perinatal, and neonatal outcomes. JAMA. 2019;322:145. https://doi.org/10.1001/jama.2019.8734.

Dickson B, Mansfield C, Guiahi M, Allshouse AA, Borgelt LM, Sheeder J, et al. Recommendations from cannabis dispensaries about first-trimester cannabis use. Obstet Gynecol. 2018;131:1031-8. https://doi.org/10.1097/AOG. 0000000000002619

Dolcinar S, Grun B, Leisch F, Schmidt K. Required sample sizes for data-driven market segmentation analyses in tourism. J Travel Res. 2014;53:296-306. https://doi.org/10.1177/0047287513496475.

Ehlert KM, Faber CJ, Kennedy MS, Benson L. Utilizing cluster analysis of closeended survey responses to select participants for qualitative data collection. Columbus: Proceedings of the 124th American Society for Engineering Education annual (ASEE) conference \& exposition; 2017.

Etxebarria, Mujika, Pyne. Training and competition readiness in triathlon. Sports. 2019:7:101. https://doi.org/10.3390/sports7050101.

Fairchild A, McDaniel H. Best (but oft-forgotten) practices: mediation analysis. Am J Clin Nutr. 2017;105:1259-71 https://academic.oup.com/ajcn/articleabstract/105/6/1259/4569799. Accessed 1 Oct 2019.

Fazio R, Powell M, Social PH-J of P and, 1983 undefined. Toward a process model of the attitude-behavior relation: accessing one's attitude upon mere observation of the attitude object. J Pers Soc Psychol. 1983;44:723 https:// psycnet.apa.org/record/1983-32702-001. Accessed 15 Aug 2019.

Fazio RH. How do attitudes guide behavior. Found Soc Behav. 1986;1:204-43 https://www.researchgate.net/profile/Russell_Fazio/publication/240032990_ How_do_attitudes_guide_behavior/links/0c96052f38293db 1bb000000/How do-attitudes-guide-behavior.pdf. Accessed 14 Aug 2019.

Gates P, Todd S, Prev JC-JA, 2017 undefined. Survey of Australian's knowledge, perception and use of cannabis for medicinal purposes. J Addict Prev. 2017 5:10 https://researchers.mq.edu.au/files/99511536/Publisher_version_open_ access_pdf. Accessed 19 Aug 2019.

Gil F, de Andrade AG, Castaldelli-Maia JM. Discussing prevalence, impacts, and treatment of substance use disorders in athletes. Int Rev Psychiatry. 2016;28: 572-8. https://doi.org/10.1080/09540261.2016.1212821.

Green B, Kavanagh D, Young R. Being stoned: a review of self-reported cannabis effects. Drug Alcohol Rev. 2003;22:453-60. https://doi.org/10.1080/ 09595230310001613976.

Hainline B, Derman W, Vernec A, Budgett R, Deie M, Dvorák J, et al. International Olympic Committee consensus statement on pain management in elite athletes. Br J Sports Med. 2017;51:1245-58. https://doi.org/10.1136/bjsports2017-097884.

Haug NA, Kieschnick D, Sottile JE, Babson KA, Vandrey R, Bonn-Miller MO. Training and practices of cannabis dispensary staff. Cannabis cannabinoid Res. 2016;1:244-51. https://doi.org/10.1089/can.2016.0024.

Hayes AF. Introduction to mediation, moderation, and conditional process analysis : a regression-based approach. 2nd ed. New York: Guilford Press; 2017. https://www.guilford.com/books/Introduction-to-MediationModeration-and-Conditional-Process-Analysis/Andrew-Hayes/9781462534654. Accessed 14 Aug 2019.

Henry D, Dymnicki AB, Mohatt N, Allen J, Kelly JG. Clustering methods with qualitative data: a mixed-methods approach for prevention research with small samples. Prev Sci. 2015;16:1007-16. https://doi.org/10.1007/s11121-0150561-z.

Hwang J, Arneson T, St Peter W. Minnesota pharmacists and medical cannabis: a survey of knowledge, concerns, and interest prior to program launch. P T. 2016;41:716-22 http://www.ncbi.nlm.nih.gov/pubmed/27904305. Accessed 16 Aug 2019.

Kuhlemeier H, Van Den Bergh H, Lagerweij N. Environmental knowledge, attitudes, and behavior in Dutch secondary education. J Environ Educ. 1999; 30:4-14. https://doi.org/10.1080/00958969909601864.

Lucas P, Baron EP, Jikomes N. Medical cannabis patterns of use and substitution for opioids \&amp; other pharmaceutical drugs, alcohol, tobacco, and illicit substances; results from a cross-sectional survey of authorized patients. Harm Reduct J. 2019;16. https://doi.org/10.1186/s12954-019-0278-6.

Macaulay AP, Griffin KW, Gronewold E, Williams C, Botvin GJ. Parenting practices and adolescent drug-related knowledge, attitudes, norms and behavior. J Alcohol Drug Educ. 2005;49:67 https://www.researchgate.net/profile/ Kenneth_Griffin2/publication/232529854_Parenting_Practices_and_ Adolescent_Drug-Related_Knowledge_Attitudes_Norms_and_Behavior/links/ Odeec53754ce35259f000000.pdf. Accessed 15 Aug 2019.

MacKinnon DP, Fairchild AJ, Fritz MS. Mediation analysis. Annu Rev Psychol. 2007; 58:593-614. https://doi.org/10.1146/annurev.psych.58.110405.085542.

Manzanares J, Julian MD, Carrascosa A. Role of the cannabinoid system in pain control and therapeutic implications for the Management of Acute and Chronic Pain Episodes. Curr Neuropharmacol. 2006;4:239-57 https://www. ncbi.nlm.nih.gov/pmc/articles/PMC2430692/pdf/CN-4-3-239.pdf. Accessed 15 Jan 2019.

Martinez LS, Lewis N. A mediation model to explain the effects of information seeking from media and interpersonal sources on Young adults' intention to use marijuana. Int J Commun. 2016;10:1809-32 http://ijoc.org/index.php/ijoc/ article/view/4402. Accessed 16 Aug 2019.

McDuff D, Stull T, Castaldelli-Maia JM, Hitchcock ME, Hainline B, Reardon CL. Recreational and ergogenic substance use and substance use disorders in elite athletes: a narrative review. Br J Sports Med. 2019;53:754-60.

Metrik J, Kahler CW, McGeary JE, Monti PM, Rohsenow DJ. Acute effects of marijuana smoking on negative and positive affect. J Cogn Psychother. 2011; 25. https://doi.org/10.1891/0889-8391.25.1.31.

Moeller KE, Woods B. Pharmacy students' knowledge and attitudes regarding medical marijuana. Am J Pharm Educ. 2015;79:85. https://doi.org/10.5688/ ajpe79685.

Monte AA, Shelton SK, Mills E, Saben J, Hopkinson A, Sonn B, et al. Acute illness associated with cannabis use, by route of exposure. Ann Intern Med. 2019. https://doi.org/10.7326/M18-2809.

MultiSport Research. Endurance sport social analytics - data - Q4 2018; 2018. https://www.multisportresearch.com/product-page/endurance-sport-socialanalytics-data-q4-2018. Accessed 21 Feb 2020.

Njoroge MW, Kenyatta J. Knowledge, attitude and practices on substance use disorders by university students: a review of literature; 2017.

O'Connell M, Sandgren M, Frantzen L, Bower E, Erickson B. Medical cannabis: effects on opioid and benzodiazepine requirements for pain control. Ann Pharmacother. 2019:106002801985422. https://doi.org/10.1177/ 1060028019854221

O'Laughlin KD, Martin MJ, Ferrer E. Cross-sectional analysis of longitudinal mediation processes. Multivar Behav Res. 2018;53:375-402. https://doi.org/10. 1080/00273171.2018.1454822.

Ozisik L, Basaran NC, Oz SG, Guven GS, Tanriover MD. Perceptions and attitudes of patients about adult vaccination and their vaccination status: still a long way to go? Med Sci Monit. 2017;23:3178-84. https://doi.org/10.12659/msm. 901856.

Park J-Y, Wu L-T. Prevalence, reasons, perceived effects, and correlates of medical marijuana use: a review. Drug Alcohol Depend. 2017;177:1-13. https://doi. org/10.1016/j.drugalcdep.2017.03.009.

Peiper NC, Gourdet C, Meinhofer A, Reiman A, Reggente N. Medical decisionmaking processes and online behaviors among cannabis dispensary staff. Subst Abus. 2017;11:1178221817725515. https://doi.org/10.1177/ 1178221817725515

Punj G, Stewart DW. Cluster analysis in marketing research: review and suggestions for application corporate social responsibility (CSR) view project. J Market Res. 1983:134-48 https://www.researchgate.net/ publication/215666129. Accessed 18 Jan 2019.

Q Market Research. Attitudes on marijuana survey: Young adults ages 18 to 25 in the New York area who attend college; 2015. Minnesota. 
Register-Mihalik JK, Guskiewicz KM, Valovich McLeod TC, Linnan LA, Mueller FO, Marshall SW. Knowledge, attitude, and concussion-reporting behaviors among high school athletes: a preliminary study. J Athl Train. 2013;48:645-53. https://doi.org/10.4085/1062-6050-48.3.20.

Running USA (2017) 2017 National Runner Survey. http://cdn.trustedpartner.com/ docs/ibrary/RunningUSA2012/RunningUSA_NRS_2017.pdf. Accessed 22 Jan 2019.

Sagy I, Bar-Lev Schleider L, Abu-Shakra M, Novack V. Safety and efficacy of medical cannabis in fibromyalgia. J Clin Med. 2019;8:807. https://doi.org/10. 3390/jcm8060807.

Satterlund TD, Lee JP, Moore RS. Stigma among California's medical marijuana patients. J Psychoactive Drugs. 2015;47:10-7. https://doi.org/10.1080/ 02791072.2014 .991858$.

Sellers CM, McManama O'Brien KH, Hernandez L, Spirito A. Adolescent alcohol use: the effects of parental knowledge, peer substance use, and peer tolerance of use. J Soc Soc Work Res. 2018;9:69-87. https://doi.org/10.1086/ 695809.

Shover CL, Davis CS, Gordon SC, Humphreys K. Association between medical cannabis laws and opioid overdose mortality has reversed over time. Proc Natl Acad Sci U S A. 2019;116:12624-6.

Siegel JT, Tan CN, Navarro MA, Alvaro EM, Crano WD. The power of the proposition: frequency of marijuana offers, parental knowledge, and adolescent marijuana use. Drug Alcohol Depend. 2015;148:34-9. https://doi. org/10.1016/j.drugalcdep.2014.11.035.

Stubbs B, Vancampfort D, Firth J, Schuch FB, Hallgren M, Smith L, et al. Relationship between sedentary behavior and depression: a mediation analysis of influential factors across the lifespan among 42,469 people in lowand middle-income countries. J Affect Disord. 2018;229:231-8. https://doi. org/10.1016/J.JAD.2017.12.104.

The Official Website - USA Cycling (2018). Active member report https://legacy. usacycling.org/corp/demographics.php. Accessed 22 Jan 2019.

USA Triathlon. USA triathlon: membership report 2016; 2016. p. 1-17.

Valente T, Paredes P, Poppe P. Matching the message to the process: the relative ordering of knowledge, attitudes, and practices in behavior change research. Hum Commun Res. 1998;24:366-85 https://academic.oup.com/hcr/articleabstract/24/3/366/4554700. Accessed 1 Oct 2019.

Volkow ND, Baler RD, Compton WM, Weiss SRB. Adverse health effects of marijuana use. N Engl J Med. 2014;370:2219-27.

Wang J, Simons-Morton BG, Farhat T, Farhart T, Luk JW. Socio-demographic variability in adolescent substance use: mediation by parents and peers. Prev Sci. 2009;10:387-96. https://doi.org/10.1007/s11121-009-0141-1.

Ware MA, Jensen D, Barrette A, Vernec A, Derman W. Cannabis and the health and performance of the elite athlete. Clin J Sport Med. 2018;28:480-4. https://doi.org/10.1097/JSM.0000000000000650.

Wu L-T, Swartz MS, Brady KT, Hoyle RH. Perceived cannabis use norms and cannabis use among adolescents in the United States. J Psychiatr Res. 2015; 64:79-87. https://doi.org/10.1016/J.JPSYCHIRES.2015.02.022.

Zeiger JS, Silvers WS, Fleegler EM, Zeiger RS. Cannabis use in active athletes: behaviors related to subjective effects. PLoS One. 2019a;14:e0218998. https:// doi.org/10.1371/journal.pone.0218998.

Zeiger JS, Silvers WS, Fleegler EM, Zeiger RS. Age related differences in cannabis use and subjective effects in a large population-based survey of adult athletes. J Cannabis Res. 2019b;1:6. https://doi.org/10.1186/s42238-019-0006-9.

\section{Publisher's Note}

Springer Nature remains neutral with regard to jurisdictional claims in published maps and institutional affiliations.

Ready to submit your research? Choose BMC and benefit from:
- fast, convenient online submission
- thorough peer review by experienced researchers in your field
- rapid publication on acceptance
- support for research data, including large and complex data types
- gold Open Access which fosters wider collaboration and increased citations
- maximum visibility for your research: over 100M website views per year
At BMC, research is always in progress.
Learn more biomedcentral.com/submissions

